pseudoanemia por crioaglutininas (7), incluso en un paciente afecto de AHAI por anticuerpos calientes, como es este caso, para no retrasar ni el diagnóstico ni su correcto tratamiento y para evitar una terapia transfusional -nos dará además problemas en las pruebas cruzadas-o inmunosupresora innecesaria en anemias compensadas y bien toleradas, como en nuestro caso.

J.A. García-Erce, M. Dobón Rebillo, L. Marzo Lafuente, C. Salvador Osuna, M. Giralt

Servicio de Hematología-Hemoterapia. Hospital Miguel Servet. Zaragoza

1. Kelton JG, Crowther M. Autoinmune hemolytic anemia. En: Brain MJ, Carbone PP, ed. Current Therapy in Hematology-Oncology. $5^{\mathrm{a}}$ ed. St. Louis: Mosby 1995; 89-94.

2. Martínez López J, Ayala Díaz, Bornsteins Sánchez R. Anemias hemolíticas en el adulto. Medicine 1996; 7: 1206-1212.

3. Shulman IA, Branch DR, Nelson JM, Thompson JC, Saxena S, Petz LD. Autoinmune hemolytic anemia with both cold and warm autoantibodies. JAMA 1985; 254: 1746-8.

4. Sokol RJ, Hewitt S, Stamps BK. Autoimmune hemolysis: an 18-year study of 865 cases referred to a regional transfusion centre. Br Med J (Clin Res Ed) 1981; 282: 2023-7.

5. Sokol RJ, Hewitt S, Stamps BK. Autoimmune hemolysis: mixed warm and cold antibody type. Acta Haematol 1983; 69: 266-74

6. Phan-Dinh- Tuy F, Habibi R, Bach MA, Chatenoud L, Salmon C, Bach JF. T cell subpopulations defined by monoclonal antibodies in autoimmune hemolytic anemia. Biomed Pharmacother 1983; 37: 75-80.

7. Cooper Ba. Autoinmune hemolytic anemia. En: Brain MJ, Carbone PP, ed. Current Therapy in Hematology-Oncology. $5^{\mathrm{a}}$ ed. St. Louis: Mosby, 1995; 53-57

\section{Tuberculosis de colon: dificultades diagnósticas actuales}

\section{Sr. Director:}

La tuberculosis intestinal era considerada la complicación más frecuente de la tuberculosis pulmonar activa en la primera mitad de nuestro siglo. Sin embargo, desde la introducción de los tuberculostáticos y la erradicación de la tuberculosis entre el ganado vacuno, ha pasado a ser una rareza en nuestro medio $(1,2)$. A nivel intestinal las lesiones tuberculosas pueden llegar a ser difícilmente diferenciables tanto desde el punto de vista clínico como analítico, radiológico y endoscópico de otros procesos infecciosos, inflamatorios o neoplásicos más prevalentes en la actualidad (1-5). Se presenta un caso que ilustra estas dificultades:

Mujer de 88 años con antecedentes de tuberculosis pulmonar a los 20 años y estreñimiento habitual. Consultó por fiebre de $39^{\circ} \mathrm{C}$ con escalofríos junto a síndrome diarreico en forma de 4 deposiciones al día sin productos patológicos de una semana de evolución. La exploración mostró una paciente afectada, pálida y la palpación abdominal reveló una fosa ilíaca derecha discretamente dolorosa, sin signos de irritación peritoneal, y con sensación de estar ocupada. En la analítica destacaba: VSG $78 \mathrm{~mm} / \mathrm{h}$, hematocrito $0,28 \mathrm{~L} / \mathrm{l}$, hemoglobina $94 \mathrm{~g} / \mathrm{l}$, VCM $81 \mathrm{fl}$, HCM 26 pg, sideremia $4,5 \mu \mathrm{mol} / \mathrm{l}$, ferritina $34 \mathrm{ng} / \mathrm{ml}$, leucocitos $16,9 \times 10^{9} / 1(85 \%$ segmentados, $7 \%$ linfocitos, $8 \%$ monocitos), plaquetas $482 \times$ 10\%/, AST $57 \mathrm{U} / 1$, ALT $49 \mathrm{U} / 1$ y proteínas totales $55 \mathrm{~g} / \mathrm{l}$ (albúmina $29 \mathrm{~g} / \mathrm{l}$ ). La radiografía de tórax evidenció imágenes cicatriciales en ambos vértices pulmonares, compatibles con proceso específico antiguo. Dos hemocultivos fueron negativos. Se inició tratamiento con cefotaxima y la paciente quedó afebril. Para el estudio de la anemia se practicó un enema opaco (Fig. 1) que mostró dos áreas estenóticas en colon transverso escasamente distensibles, concéntricas y con espiculación de borde inferior junto a un defecto de replección en ciego. El CEA fue inferior a
0,5 ng/ml. Una ecografía abdominal reveló en fosa ilíaca derecha una imagen de seudorriñón que se correspondía a un ciego de paredes engrosadas y áreas hipoecoicas compatibles con zonas de necrosis. Se realizó una fibrocolonoscopia que visualizó una estenosis ulcerada al inicio del colon transverso que ocupaba la mitad de su circunferencia, así como una segunda área ulcerada de aspecto infiltrativo al final del colon transverso. A nivel del ciego se observó una formación exofítica y de aspecto degenerado. Todas las lesiones fueron biopsiadas. Tras estos resultados se procedió a valorar la solución quirúrgica de la supuesta neoplasia. El día previo a la intervención se recibieron los resultados de las biopsias que informaban de la presencia de una colitis granulomatosa con presencia de bacilos ácido-alcohol resistentes en las tres zonas. Una TC torácica de alta resolución mostró las mismas lesiones que la radiología simple. Tres cultivos de Lowënstein de aspirados nasogástricos (la paciente no expectoraba) fueron negativos. Se prescribió tratamiento tuberculostático con isoniacida, rifampicina y pirazinamida durante 9 meses que finalizó sin complicaciones.

La tuberculosis es una enfermedad frecuente en nuestro país que además ha visto incrementada su incidencia en la última década debido fundamentalmente a la aparición del virus de la inmunodeficiencia humana $(\mathrm{VIH})$ y en menor grado a la inmigración del Tercer Mundo (6). Todo ello ha dado lugar a la reaparición de formas atípicas casi inexistentes en épocas recientes (7) frente a las cuales el clínico actual, incluso ante cuadros clásicos, tiene dificultades para reconocerlas y para planteárselas como alternativas diagnósticas cuando no se dan los supuestos mencionados de inmigración o de pacientes infectados por el VIH. A ello contribuye en el caso de la tuberculosis intestinal, su amplia expresividad clínica $(1,8)$ y a que sólo un $20 \%$ de pacientes presente a la vez enfermedad pulmonar evidente. De esta manera no extraña que sea con frecuencia confundida con otras patologías más frecuentes en la práctica actual como la enfermedad inflamatoria intestinal, la neoplasia de colon, el linfoma intestinal o la diverticulitis o incluso en menor medida con la amiloidosis y la amebiasis $(3,4,9,10)$. Finalmente, creemos que casos como el presentado nos recuerda a las puertas del siglo XXI la necesidad

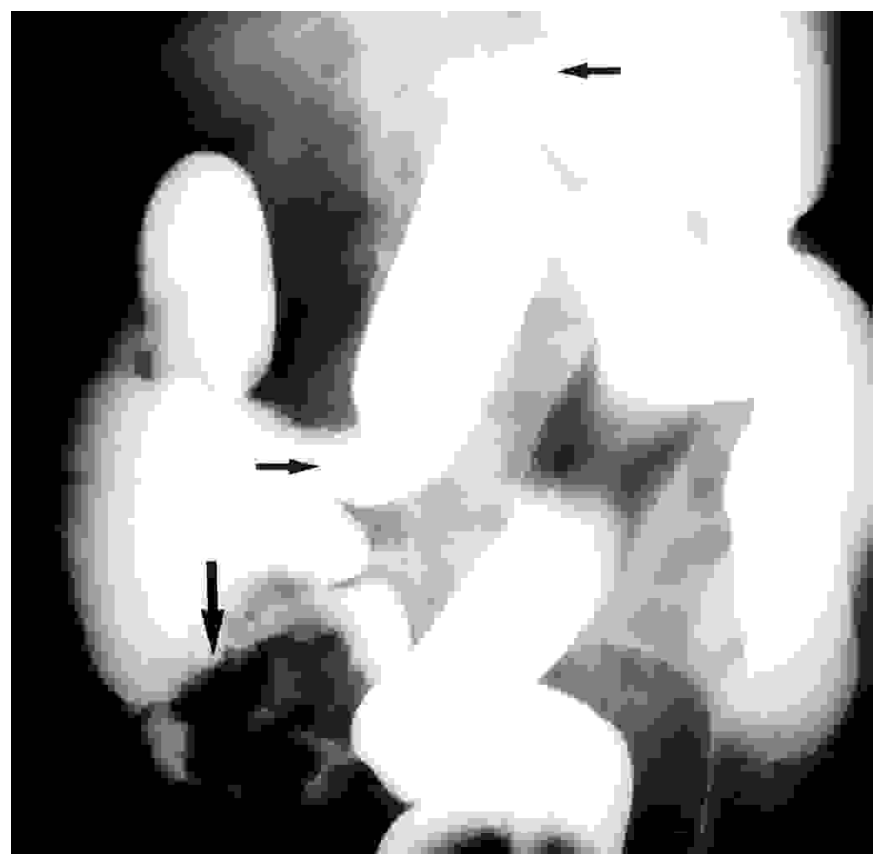

Fig. 1. El enema opaco pone en evidencia la existencia de 2 lesiones estenóticas a nivel proximal $(\rightarrow)$ y distal $(\leftarrow)$ de colon transverso y la presencia de un gran defecto de replección de morfología exofítica a nivel del ciego $(\downarrow)$. 
de seguir conservando en nuestros esquemas diagnósticos a la tuberculosis en cualquiera de sus formas incluso aquellas que parecerían propias de otras épocas.

\section{F. Olid Cobos, E. Mariscal Labrador, V. Garriga Farriol*, J. Esquius Soriguera**, E. Pedrol Clotet}

Unidad de Infecciones/VIH. Servicios de *Radiodiagnóstico y de **Anatomía Patológica. Hospital General. Granollers. Barcelona

1. Marshall JB. Tuberculosis of the gastrointestinal tract and peritoneum. Am J Gastroenterol 1993; 88: 989-99.

2. Moral A, Piulachs J, Bombí JA, Targarona EM, Novell F, Trías M Tuberculosis gastrointestinal: un caso de estenosis cecal. Rev Esp Enf Digest 1992; 81: 213-4

3. Gómez-Rubio M, de Cuenca B, Opio V, Ulloa J, García J. Colonic tuberculosis. An unusual endoscopic diagnosis. Endoscopy 1993; 25: 377.

4. Singh V, Kumar P, Kamal J, Prakash V, Vaiphei K, Singh K. Clinicocolonoscopic profile of colonic tuberculosis. Am J Gastroenterol 1996; 91: 565-68

5. Ahmed FB, Scott J, Hodgson HJF, Oakley CM, Frienland JS, Ind PW et al. Tuberculous enteritis. A serious possibility in some patients. BMJ 1996; 313: 215-7.

6. Mellado B, Pedrol E, Casademont J, Grau JM. Absceso subcutáneo tuberculoso como forma de presentación de un síndrome de inmunodeficiencia adquirida. Rev Clin Esp 1993; 192: 95-96.

7. Pedrol E, Estruch R, Barceló J, Urbano-Márquez A. Tonsillar and pharingeal tuberculosis in a patient without HIV antibodies. J Infect Dis 1989; 159: 598

8. Horvath KD, Whelan RL, Weinstein S, Basner AL, Staugaitis SM, Greenebaum E. Isolated sigmoid tuberculosis. Dis Colon Rectum 1995; 38 : 1327-30.

9. Vázquez M, Díaz JL, Gallego JC. Tuberculosis colónica. Rev Clin Esp 1993; 192: 238-9.

10. Medina E, Orti E, Tomé A, Quiles F, Canelles P, Mertinez A. Segmental tuberculosis of the colon diagnosed by colonoscopy. Endoscopy 1990; 22: 188-90.

\section{Neurolúes, demencia y mioclonias}

\section{Sr. Director}

La sífilis puede afectar a diversos órganos de forma variable. El Sistema nervioso central se afecta por invasión meningea durante el estadio secundario y se manifiesta generalmente con cefalea, vértigo, insomnio, trastornos psíquicos y accidentes cerebrovasculares (1). La aparición de mioclonias como primer síntoma de neurosífilis es rara. Por su infrecuencia comunicamos un caso de neurosífilis y mioclonias de acción que desaparecieron tras el tratamiento con penicilina.

Varón de 60 años de edad, sin antecedentes patológicos de interés, que acudió al hospital por desorientación progresiva y aparición reciente de contracciones involuntarias en extremidades superiores. Negaba historia previa de exposición a tóxicos, traumatismos, fármacos ni alteraciones neurológicas. De la exploración física destacaba la existencia de mioclonias espontáneas y desencadenadas por estímulos sensoriales en tronco y extremidades superiores. El resto de la exploración neurológica era normal, excepto desorientación temporo-espacial y alteraciones de la memoria a corto y largo plazo. No se objetivaron lesiones cutáneo-mucosas. Las exploraciones complementarias (incluyendo serología frente al VIH), únicamente demostraron discreta neutrofilia y VSG elevada. El análisis del LCR demostró pleocitosis linfocitaria, proteinorraquia y glucosa normal. Fue positiva la serología luética en sangre y LCR. La TAC craneal fue normal y, el EEG mostró trazado de base normal con descargas periódicas. Con el diagnóstico de neurolúes se instauró tratamiento con penicilina $\mathrm{G}$ sódica con lo que remitieron las mioclonias y mejoró progresivamente el status mental.

Existen múltiples causas de mioclonias de acción, entre las que destacan, las infecciones víricas del SNC como la panencefalitis esclerosante subaguda y la encefalitis herpética (2). Se han descrito también en el contexto de infección por VIH. Por otra parte la afección del sistema nervioso central en la sífilis suele iniciarse por invasión meninge durante el estadío secundario y puede ser asintomática, manifestarse como neurosífilis parenquimatosa, meningitis sifilítica o sífilis meningovascular (3). Se han descrito alteraciones patológicas en distintas estructuras del SNC, a ellas puede sumarse una arteritis que produzca isquemia a diferentes niveles del parénquima. Revisando la literatura encontramos 3 casos similares (5-7) y, en el nuestro, a pesar de que las técnicas de neuroimagen no evidenciaron lesión que explicara las mioclonias, la buena respuesta de éstas a la penicilina, sugiere relación causal con la infección por el Treponema pallidum. En una época de incremento en la incidencia, cierta precocidad de la clínica y presentaciones atípicas de neurolúes la presencia de mioclonias aisladas obliga a incluirla en el diagnóstico diferencial.

\section{G. Pía Iglesias, C. González González, E. Ameneiros Lago, P Sesma Sánchez*}

Servicio de Medicina Interna. *Departamento de Medicina USC. Complejo Hospitalario A. Marcide-Novoa Santos. Ferrol (A Coruña)

1. Simon RP. Neurosyphilis. Arch Neurol 1985; 42: 606-613.

2. Lance JW. Action myoclonus, Ransay Hunt Syndrome and other Cerebellar Myoclonic Syndromes. En: Fhan S, Marsden CD, Van Woert M, eds. Advances in Neurology, vol 43: Myoclonus. New York, Raven Press, 1986; 33-35.

3. Hook EW, Marra CM. Adquired syphilis in adults. N Engl J Med 1992; 326: 1060-1069.

4. Powell AL, Coyne AC, Jen L. A retrospective study of syphilis seropositivity in a cohort of demented patients. Alzheimer Dis Assoc Disord. 1993; 7: 33-8.

5. Pérez de Colosia V, Mateos V, Salas-Puig J, Lahoz CH. Mioclonias de acción en un caso de paralisis general progresiva. Neurología 1992: 7: 235-6.

6. Repiso T, Garcia-Patos V, Aleman C, Castells Rodellas A. Mioclonias y sifílides psoriasiformes en un caso de sífilis tardía. Med Clin (Barc) 1995; 104: 556.

7. Heide G; Lindemuth R; Schimrigk K Generalized myoclonus as the only symptom of neurosyphilis . Nervenarzt 1997; 68: 845-7. 